\title{
Thrombectomy in Acute Ischemic Stroke: Challenges to Procedural Success
}

\author{
Albert J. Yoo, ${ }^{\mathrm{a}}$ Tommy Andersson ${ }^{\mathrm{b}, \mathrm{c}, \mathrm{d}}$ \\ aTexas Stroke Institute, Dallas-Fort Worth, TX, USA \\ ${ }^{b}$ Department of Neuroradiology, Karolinska University Hospital, Stockholm, Sweden \\ 'Department of Clinical Neuroscience, Karolinska Institutet, Stockholm, Sweden \\ dDepartment of Medical Imaging, AZ Groeninge, Kortrijk, Belgium
}

The overwhelming clinical benefit of intra-arterial stroke therapy owes to the major advance in revascularization brought on by the current generation of thrombectomy devices. Nevertheless, there remains a sizeable proportion of patients for whom substantial reperfusion cannot be achieved or is achieved too late. This article addresses the persistent challenges that face neurointerventionists and reviews technical refinements that may help to mitigate these obstacles to procedural success. Insights from in vitro modeling and clinical research are organized around a conceptual framework that examines the interaction between the device, the thrombus and the vessel wall.

Keywords Acute ischemic stroke; Intra-arterial therapy; Endovascular therapy; Thrombectomy; Thrombus

\author{
Correspondence: Tommy Andersson \\ Department of Medical Imaging, AZ \\ Groeninge, President Kennedylaan 4, \\ 8510 Kortrijk, Belgium \\ Tel: +32-471-434241, \\ $+46-73-9661917$ \\ E-mail: tommy.andersson99@gmail.com
}

Received: April 16, 2017

Revised: May 24, 2017

Accepted: May 24, 2017

AJY reports research grants from Penumbra Inc. and Neuravi/Codman Neurovascular Inc. TA is a consultant for Ablynx, Amnis Therapeutics, Medtronic, Neuravi (J\&), Rapid Medical and Stryker.

The authors have no financial conflicts of interest.

\section{Introduction}

In acute ischemic stroke (AIS), the overwhelming clinical benefit of intra-arterial treatment (IAT) seen in the recent randomized trials owes primarily to the effectiveness of stent retrievers. ${ }^{1-5}$ With this device class, substantial reperfusion is routinely achieved in 70-80\% of cases. In addition, large-bore aspiration catheters have emerged as an alternative means of achieving similarly high revascularization rates. ${ }^{6}$ However, there remains a sizeable minority of patients in whom the thrombus cannot be removed using the current approaches. This subgroup represents the next challenge for the neurointerventional field. This review will provide a conceptual framework for understanding how thrombus characteristics and procedural techniques may impact the success of IAT including problems associated with vascular access and thrombus removal, and will highlight areas requiring further research.

\section{Revascularization results in the current era}

The current benchmark for technical success of the endovascular procedure is a modified Treatment in Cerebral Ischemia (mTICl) 2b-3 score (reperfusion in greater than 50\% of the target ischemic territory). ${ }^{7.8}$ As compared to the Merci retriever, the $\mathrm{mTICl} 2 \mathrm{~b}-3$ rates have roughly doubled with the current devices (Figure 1) ${ }^{9-11}$ As technology improves, this angiographic endpoint may be less able to discriminate device superiority owing to a ceiling effect. For this reason, $\mathrm{mTICl} 2 \mathrm{c}-3$ (>90\% target territory reperfusion) will likely be a more useful endpoint in future device trials. ${ }^{7}$ Currently, rates of complete reperfusion are 
approaching 50\% (Table 1). ${ }^{12-15}$ Devices and techniques that are less prone to clot fragmentation should improve these results, but there is a likely upper limit to this rate determined by the prevalence of distal emboli at baseline. Unfortunately, it is difficult to identify distal occlusions on noninvasive vascular imaging, given the number of distal branches to evaluate and the variability of contrast opacification in the ischemic bed due to collateral differences between patients. Currently, the most accurate way to visualize the presence of additional downstream thrombi is using susceptibility weighted MRI. In one study utilizing this technique, multiple thrombi were present in $7.4 \%$ of

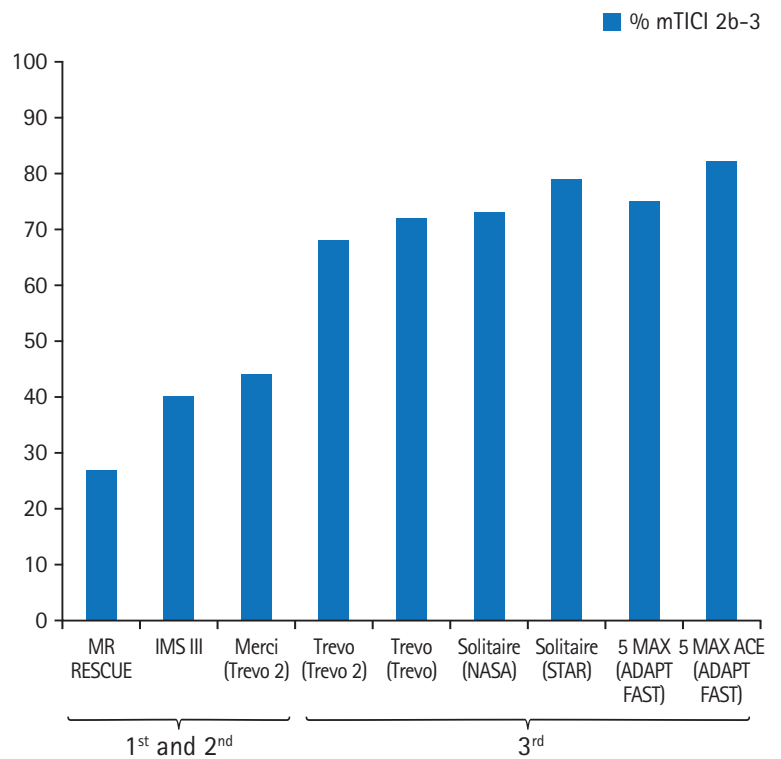

Figure 1. Evolution of $\mathrm{mTICl} 2 b-3$ rates. First generation device $=$ Merci. Second generation = initial smaller bore Penumbra catheters. Third generation = stent-retrievers and large-bore aspiration catheters (e.g., Penumbra 5 MAX ACE and larger). mTICl, modified Treatment in Cerebral Ischemia. patients (24 of 324 patients). ${ }^{16}$

The intra-procedural time to reperfusion is another critical measure of device effectiveness as well as ease of delivery, and has a direct impact on clinical outcomes. This can be reported in various ways, including the time from vessel access to reperfusion or from guide catheter placement to reperfusion, and the rate of first-pass success. The steady decline in the time to revascularization also accounts for the clinical success of the latest generation devices (Figure 2). In some studies, the average time from guide catheter to revascularization is approximately 30 minutes or less (Table 1).

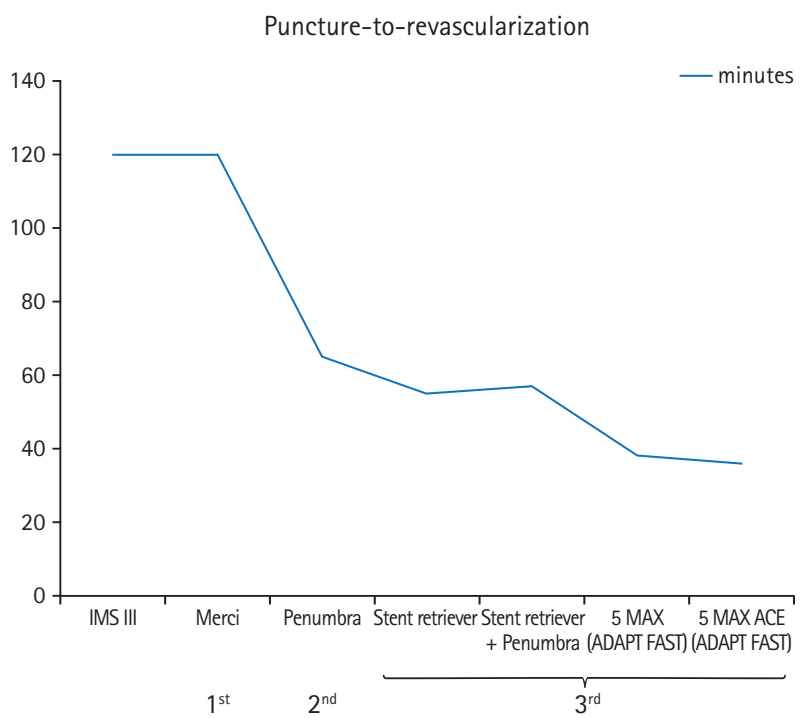

Figure 2. Evolution of procedural times. First generation device $=$ Merci. Second generation $=$ initial smaller bore Penumbra catheters. Third generation = stent-retrievers and large-bore aspiration catheters (e.g., Penumbra 5 MAX ACE and larger).

Table 1. Revascularization results with third-generation devices

\begin{tabular}{|c|c|c|c|c|}
\hline Trial & Device & $\mathrm{mTICl} 2 \mathrm{~b}-3(\%)$ & $\mathrm{mTICl} 3(\%)$ & Time from guide catheter to revasc/end ( $\mathrm{min})$ \\
\hline \multirow[t]{2}{*}{$\mathrm{SWIF}^{10}$} & Solitaire & $\mathrm{N} / \mathrm{A}$ & $\mathrm{N} / \mathrm{A}$ & 36 (median) \\
\hline & Merci & $\mathrm{N} / \mathrm{A}$ & $\mathrm{N} / \mathrm{A}$ & 52 (median) \\
\hline \multirow[t]{2}{*}{ Trevo $2^{11}$} & Trevo & 68 & 14 & 48 (mean) \\
\hline & Merci & 44 & 6 & 47 (mean) \\
\hline Trevo $^{9}$ & Trevo & 72 & 7 & $\mathrm{~N} / \mathrm{A}$ \\
\hline $\mathrm{STAR}^{12}$ & Solitaire & 79 & 55 & 20 (mean) \\
\hline NASA registry ${ }^{*, 13}$ & Solitaire & 73 & 40 & $\mathrm{~N} / \mathrm{A}$ \\
\hline Humphries et al., ${ }^{* 15}$ & Stent retriever+penumbra & 88 & 44 & $\mathrm{~N} / \mathrm{A}$ \\
\hline \multirow[t]{2}{*}{ ADAPT FAST ${ }^{*, 14}$} & Penumbra 5MAX & 75 & 41 & $38^{+}$(mean) \\
\hline & Penumbra 5MAX ACE & 82 & 61 & $36^{\dagger}($ mean $)$ \\
\hline
\end{tabular}

mTICl, modified Treatment in Cerebral Ischemia; SWIF, Solitaire With the Intention For Thrombectomy; N/A, not available; STAR, Solitaire flow restoration Thrombectomy for Acute Revascularization; NASA, North American Solitaire Acute stroke registry; ADAPT FAST, A Direct Aspiration first Pass Technique Fast. ${ }^{*}$ Not core lab adjudicated; ${ }^{\top} T i m e$ from groin puncture to $\mathrm{mTICI} \geq 2 \mathrm{~B}$ or end. 


\section{Challenges to procedural success}

Despite the groundbreaking results of the recent trials, the variability in angiographic and clinical outcomes highlight the need to further improve neurointerventional tools and techniques (Figure 3). In $15-40 \%$ of the trial populations, substantial reperfusion could not be achieved, and in probably many more, revascularization was achieved too late. The numerous challenges that can decrease the clinical effectiveness of IAT may be broadly categorized into two classes: vascular access and thrombus removal.

\section{Vascular access}

Clearly, barriers to vessel access and to adequate guide catheter support will impede or prevent device delivery to the thrombus. Unfortunately, these obstacles are most common in high-risk stroke populations. Significant peripheral vascular disease can make traditional groin access either time consuming or impossible (e.g., aorto-iliac occlusion), necessitating alternative approaches or causing early termination of the thrombectomy procedure. Similarly, in patients with certain aortic arch configurations (e.g., type III) or with significant cervical vascular tortuosity, catheterization may be significantly delayed, and placement of large-bore guide catheters may be impossible. ${ }^{17,18}$ Furthermore, in these situations, the forces required to navigate intermediate catheters and microcatheters into the intracranial circulation may result in guide catheter herniation and loss of access. This is particularly problematic for lesions involving the left anterior circulation, given the sometimes steep angulation of the origin of the left common carotid artery. In one series of 130 anterior circulation AIS patients undergoing IAT, the target artery could not be catheter-

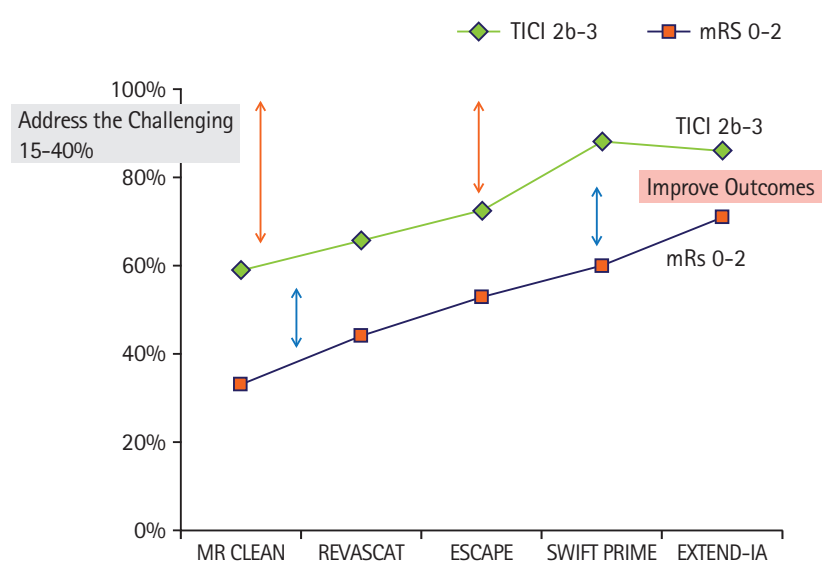

Figure 3. Variability in angiographic and clinical outcomes in the recent randomized trials of thrombectomy. $\mathrm{TICl}$ : Treatment In Cerebral Ischemia; mRS: modified Rankin Scale. ized in 2 patients due to aorto-iliac occlusion and in 5 patients due to vessel tortuosity. ${ }^{18}$ In $25 \%$ of the remaining cases, the time from groin access to carotid guide catheterization was 30 minutes or longer. In this subgroup, there was significantly decreased revascularization rate, longer time to revascularization, and worse 90-day outcomes. Predictors of difficult carotid access were age $>75$ years, hypertension, dyslipidemia, and left carotid catheterization. ${ }^{18}$

In such situations, direct puncture of the common carotid artery may be the only viable option. ${ }^{19,20}$ In one series of seven patients, direct carotid puncture was performed after multiple unsuccessful attempts from a femoral approach, which lasted from 20 to 90 minutes. ${ }^{19}$ Carotid access was achieved in 15 minutes or less in all cases (median 10 minutes), and $\mathrm{mTICl}$ $2 b-3$ reperfusion was achieved in $6(86 \%)$ patients within 7-49 minutes of access. Notably, all patients had left middle cerebral artery (MCA) occlusions. The drawbacks to this approach are the potential for respiratory compromise or cranial nerve injury from hematoma formation, and the absence of devices tailored to the shorter working distances. ${ }^{20}$

Another frequent obstacle to thrombectomy is significant stenosis or occlusion of the cervical ICA. In the recent trials, the rate of tandem occlusions ranged between $10-30 \% .{ }^{1{ }^{12,4}} \mathrm{It}$ is noteworthy that the trials with the highest $\mathrm{mTICl} 2 b-3$ rates (SWIFT PRIME and EXTEND IA) excluded such patients. ${ }^{3,5}$ In the remaining trials, there was an inverse relationship between $\mathrm{mTICl} 2 \mathrm{~b}-3$ rate and the proportion of tandem cervical occlusions. Furthermore, there will by necessity be a delay to thrombectomy as an occluded/severely stenosed ICA needs to be opened before the device maneuver. A balloon guide catheter may in such a scenario be used for proximal protection even though it is uncertain whether the flow arrest achieved in this way offers sufficient protection. In addition, if performing an acute carotid stenting in this context, the new double-layer carotid stents have been proposed to limit embolization related to plaque prolapse through the stent. ${ }^{21} \mathrm{~A}$ pertinent question is, however, whether such acute carotid stenting should be performed or the procedure limited to angioplasty alone. Although stenting helps to minimize post-angioplasty recoil, the major drawback is the need for antiplatelet therapy which can in combination with a fresh infarct and a deprived autoregulation potentially exacerbate the risk of symptomatic intracranial hemorrhage, particularly after IV rtPA. However, a recent metaanalysis of nonrandomized studies reported an acceptable overall symptomatic hemorrhage rate of 4\% (95\% confidence interval 0-10) when carotid stenting was performed in conjunction with stent retriever thrombectomy.22 Dual antiplatelet therapy was used in most of the included studies. Despite the 
added technical difficulty of treating tandem lesions, there is no justification to withhold treatment from these patients as the presence of a tandem cervical lesion did not modify treatment effect in the recent trials. ${ }^{23}$

\section{Thrombus removal}

The primary challenge for neurointerventionists is the 20-30\% of thrombi that are resistant to current retrieval approaches. In order to systematically address this challenge, it is useful to understand the interaction between the device, the thrombus, and the vessel wall, and how various factors and procedural techniques can influence this interaction (Figure 4).

\section{Thrombus-vessel interaction}

There are two primary factors that determine how much force will be required to remove the thrombus. The first is the force of impaction, which is determined by the pressure gradient across the thrombus - in other words, systemic blood pressure acting on the proximal thrombus face minus the pressure from retrograde collateral blood flow at the distal thrombus face. This factor likely explains the decreased rate of successful revascularization among patients with worse collaterals. ${ }^{24}$ The second factor is the combined force of friction and adhesion between the thrombus and the vessel wall, which will determine how "sticky" the thrombus is. In vitro experiments using thrombi of varying fibrin and red blood cell proportions have shown that fibrin-rich thrombi ( $<20 \%$ red cell content) have a significantly higher coefficient of static friction, both on a lowfriction polytetrafluoroethylene-coated plate and on harvested vessel wall tissue (Supplementary Video 1). ${ }^{25}$ This finding supports recent studies that have demonstrated decreased revascularization rates of hypodense, fibrin-rich thrombi (Supplementary Video 2). ${ }^{26}$ In addition, greater thrombus length would be expected to yield increased friction and adhesion given the larger surface area for thrombus-vessel interaction. This might

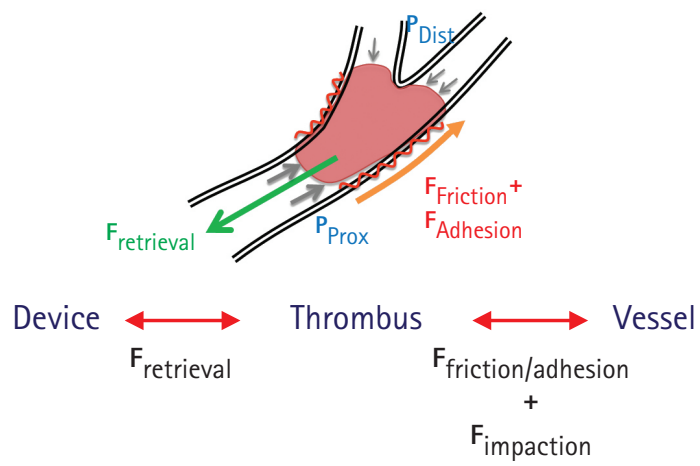

Figure 4. Device-thrombus-vessel interaction. explain in part the worse outcomes seen after aspiration thrombectomy of longer thrombi in the THERAPY trial. ${ }^{27}$

\section{Modifying device-thrombus-vessel interaction}

Clearly, the ideal interaction is one in which the force of retrieval is greater than the overall inertial force (impaction force plus friction/adhesion force). There are several procedural techniques that can potentially shift this balance to favor success.

Optimizing stent retriever integration with thrombus. The amount of retrieval force that can be transmitted to the thrombus is directly related to the degree of thrombus integration with the stent retriever. The surest way to maximize device-thrombus interaction is to appropriately position the device so that the active element (i.e., segment with full stent diameter) is deployed within the thrombus. The proximal marker at the junction of the stent and the pusher wire should be proximal to the proximal thrombus face, recognizing that there is typically a short tapered segment between the marker and the active element in most stent retrievers.

For stents with a closed-cell design (e.g., Trevo), integration can be further enhanced by pushing the stent rather than unsheathing during deployment. This will result in an increase in stent diameter (along with foreshortening). An in-vitro study by van der Marel and colleagues demonstrated that pushing resulted in significantly greater integration of the stent retriever within hard thrombi. ${ }^{28}$ Integration was high for soft thrombi, regardless of how the stent retriever was deployed. The pushing technique, therefore, addresses the potentially more difficult cases with firm thrombi, which is supported by a clinical study of Trevo thrombectomy wherein the pushing technique resulted in higher rates of first-pass reperfusion and of complete reperfusion ( $\mathrm{mTICl} 3$ ) compared to standard unsheathing. ${ }^{29}$ Finally, the study by van der Marel et al. ${ }^{28}$ showed that thrombus integration further increased at five minutes after deployment compared to immediate post-deployment measurement. However, the optimal incubation time was not studied.

Development of new devices. The most commonly used stent retrievers today are all based on the same principle, relying on the radial force to sufficiently penetrate the thrombus to achieve a grip firm enough to hold it while being removed. There are, however, new devices in different stages of development that incorporate new working principles (Table 2). Some of these devices are already approved and used, at least in some parts of the world, whereas others are still at the investigational stage.

Intermediate catheter and local aspiration. In cases with significant vessel tortuosity (e.g., S-shaped curve), placement of 
Table 2. New mechanical thrombectomy devices

\begin{tabular}{lll}
\hline Device & \multicolumn{1}{c}{ Company } & \multicolumn{1}{c}{ Working principle } \\
\hline EMBOTRAP & $\begin{array}{l}\text { Neuravi/Codman } \\
\text { Neurovascular }\end{array}$ & Open outer cage, inner flow channel, closed distal end \\
ERIC & Microvention & Interlinked cage technology with adjustable length; small (0.017) \\
TIGER TRIEVER & Rapid Medical & Adjustable diameter; strong radial force \\
GOLDEN RETRIEVER & Amnis Therapeutics & Cage formation expanding from a microwire; small (0.014) \\
LAZARUS RE-COVER & Medtronic & Cover accessory device - combined with various stent retrievers
\end{tabular}
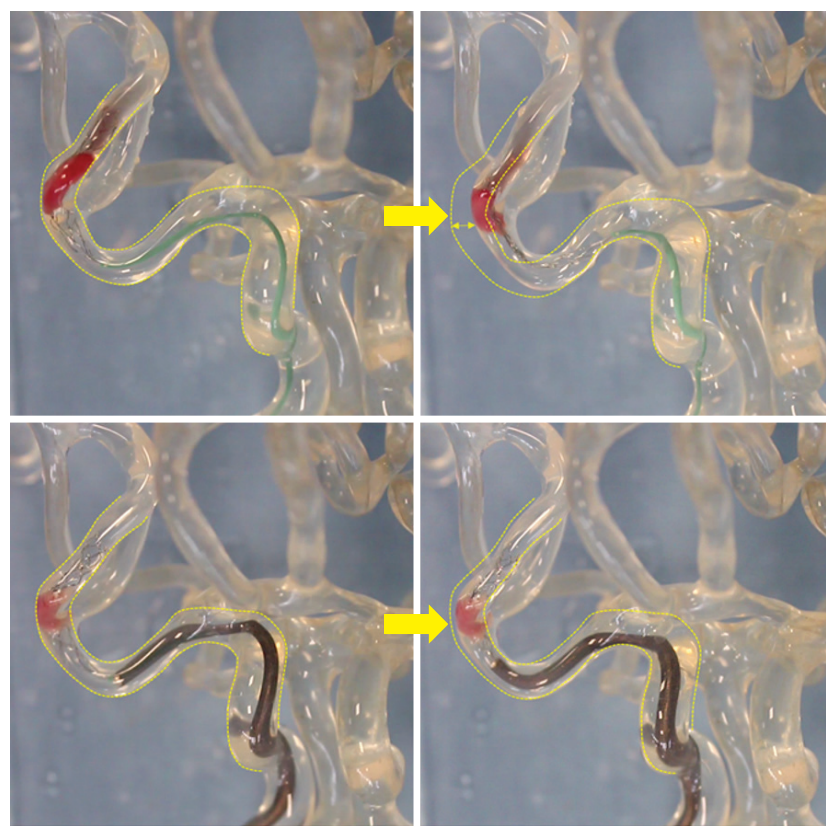

Figure 5. Line-of-force challenge. Top left image demonstrates a stent retriever deployed within a thrombus on the distal limb of an S-shaped curve. Top right image, taken during retraction of the stent retriever without an intermediate catheter, shows ineffective force transmission where some of the force deforms the original course of the vessel (depicted with the dotted lines). Bottom left image shows a stent retriever delivered through an intermediate catheter and deployed across a thrombus, again on the distal limb of an S-shaped curve. Bottom right image, taken during retraction of the stent retriever and with the intermediate catheter just proximal to the thrombus, demonstrates effective force transmission without deformation of the vessel.

an intermediate catheter (IMC) in close proximity to the thrombus ensures that the greatest effective retrieval force is generated when removing the device (Figure 5). Ideally, the most proximal $20-25 \%$ of the retriever is pulled inside the $I M C$, after which the entire construct is retracted to an inflated balloon guide catheter (BGC) with aspiration on both the IMC and the BGC, the so-called "pinning technique". ${ }^{\text {" }}$

The ability to deliver large-bore intermediate catheters to the thrombus also enables such a strong suction force that it is possible to remove a soft thrombus without a stent-retriever (ADAPT technique; Figure 6). ${ }^{14}$ The presence of an intermediate catheter alone (i.e., before suction is applied) decreases the im-

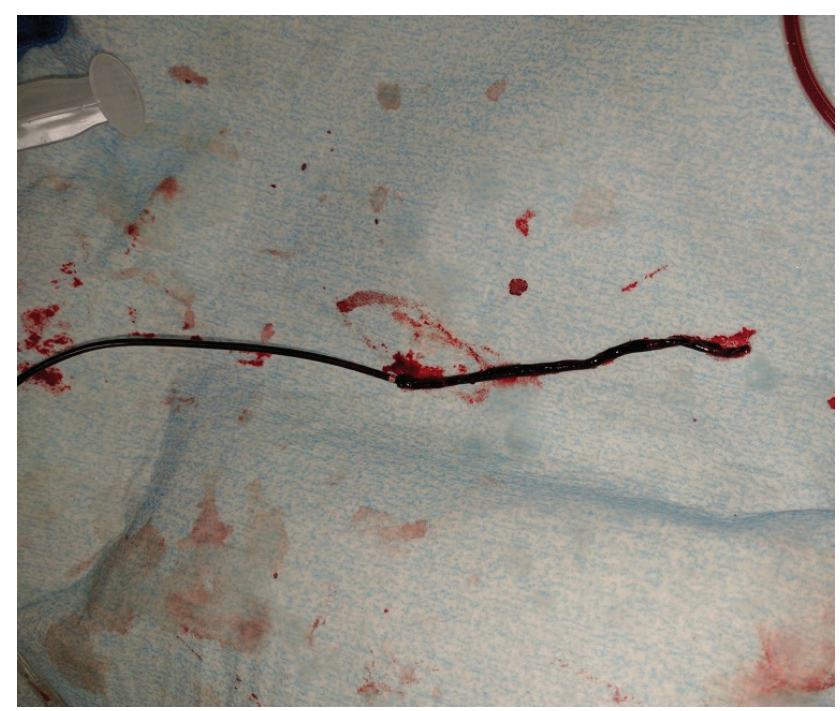

Figure 6. ADAPT. Long thrombus retrieved from a cervical internal carotid artery occlusion using the ADAPT technique through a Penumbra ACE 68 catheter.

paction force on the proximal thrombus face by the percentage of the vessel lumen cross-sectional area occupied by the catheter. When the aspiration pump is turned on, there should be a further decrease in impaction force, with one in-vitro study reporting flow reversal. ${ }^{31}$ The suction force on the thrombus be comes appreciable when the catheter tip is close to the thrombus $(<1 \mathrm{~mm})$ and increases until the catheter comes into contact with the thrombus. ${ }^{32}$ One concern is that once the thrombus is engaged, the suction forces within the vessel lumen are lost, and flow around the intermediate catheter may result in fragmentation and distal embolization during retrieval, which has been reported in an in-vitro model..$^{31}$ This may be particularly problematic when the thrombus is soft and friable. Nevertheless, the recent ASTER trial results demonstrated no significant difference in the primary outcome of final $\mathrm{mTICl} 2 b-3$ rate (i.e., after all treatments) when front-line therapy was ADAPT $(85.4 \%)$ vs. stent-retriever $(83.1 \% ; P=0.53) .{ }^{33}$ Similarly, the rates of complete reperfusion $(\mathrm{mTICl} 3)$ were $37.5 \%$ vs. $38.6 \%$ for ADAPT vs. stent-retriever, respectively ( $P=0.82)$. The use of rescue therapy was numerically higher in the ADAPT group 
(32.8\% vs. $23.8 \%, P=0.053$ ). However, the median times from groin puncture to $\mathrm{mTICl} 2 \mathrm{~b}-3$ reperfusion were shorter for ADAPT (median $31 \mathrm{~min}$ vs. $44 \mathrm{~min}$ ), which was related to a significantly faster time from thrombus contact to reperfusion (median $13 \mathrm{~min}$ vs. $23 \mathrm{~min} ; P=0.02$ ). There were no significant differences in the safety endpoints. In particular, there was no meaningful difference in embolization to a new territory (3.1\% vs. $2.1 \%$, ADAPT vs. stent-retriever; $P=0.58$ ).

Balloon guide catheter. The traditional way to achieve flow arrest during thrombectomy is using a cervical BGC. This will reduce the impaction force on the thrombus allowing for more effective retrieval, as well as minimize the tendency for thrombus fragmentation and distal embolization compared to a traditional cervical guide catheter. ${ }^{31,34}$ However, it should be recognized that full flow arrest may not be possible if there is collateral flow from the posterior communicating artery - this may explain why distal embolization is still seen with BGCs in in-vitro studies wherein the flow model includes this collateral vessel. When suction is applied through the BGC, significant flow reversal can be achieved, which in some cases can fully retrieve intracranial occlusions without the need for intracranial catheterization. ${ }^{35,36}$ In retrospective clinical studies of stent-retriever thrombectomy, BGC use was associated with improved revascularization, shorter procedure times, and better clinical outcomes. ${ }^{37,38}$ Although these data support the use of a BGC with stent retrievers, the recent ASTER results showed no advantage of this combination over a primary ADAPT approach regarding revascularization rate. However, the better clinical outcomes for stent retrievers in this study, although not statistically significant, may reflect less peripheral emboli in the primarily affected territory when used in combination with a BGC as compared to ADAPT. ${ }^{39}$ In ASTER, 92\% of the stent-retriever cases utilized a BGC versus none of the ADAPT cases (personal communication, Dr. Bertrand Lapergue).

Combined stent-retriever and local aspiration. As mentioned above, another common approach is to perform stent-retriever thrombectomy through an IMC using added local aspiration ("pinning technique"). ${ }^{30,40}$ By combining these two methods, this technique increases the retrieval force that can be generated on the thrombus as well as diminishes the line-of-force challenge of an S-configuration that may be formed by the upper carotid siphon and $\mathrm{M} 1$ segment (Figure 7). In an in-vitro model, $\mathrm{mTICl} 2 \mathrm{~b}-3$ reperfusion was significantly more frequent with the stent-retriever/aspiration approach than with a stentretriever alone..$^{30}$ In a retrospective, multicenter clinical study, the combined approach resulted in an $88 \%$ rate of $\mathrm{mTICl} 2 \mathrm{~b}-3$ reperfusion, with complete reperfusion in $44 \% .{ }^{15} \mathrm{~A}$ variant of this technique is to completely remove the stent retriever and
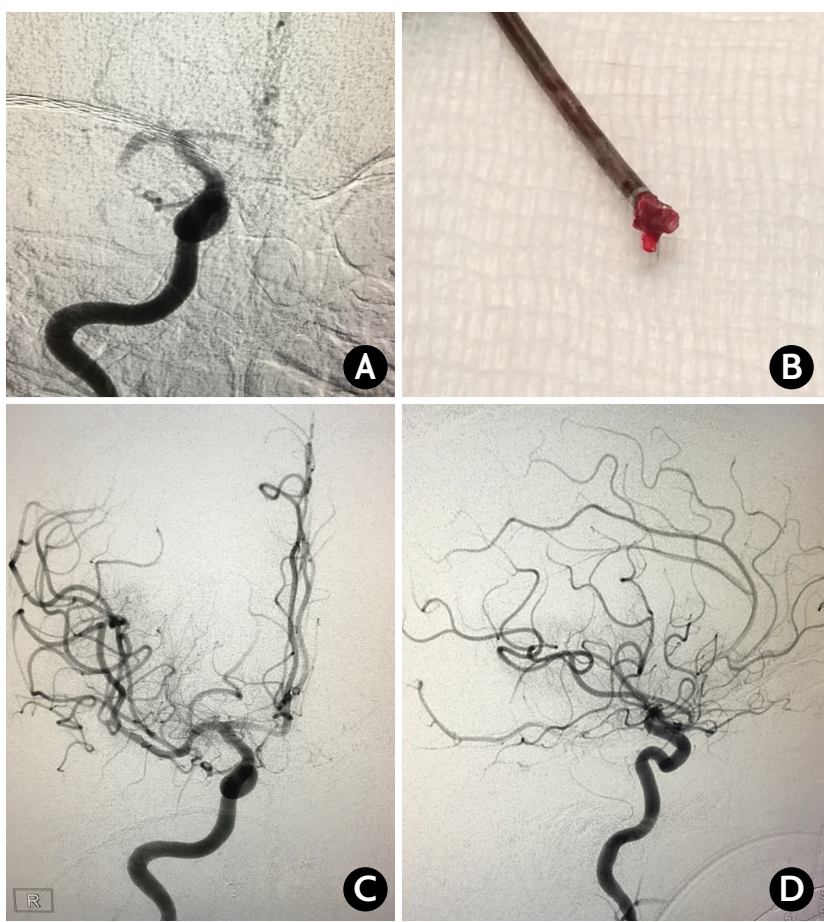

Figure 7. Combined stent-retriever/aspiration. (A) Baseline image of right MCA M1 segment occlusion. (B) Thrombus within the stent-retriever is partially captured within the aspiration catheter and removed as a single unit. (C and D) Final AP and lateral image demonstrating $\mathrm{mTICI} 2 \mathrm{c}$ reperfusion. Notice the $\mathrm{S}$-shaped configuration of the supraclinoid ICA and M1 segment. MCA, middle cerebral artery; AP, FULL NAME; mTICl: modified Treatment In Cerebral Ischemia; ICA, internal carotid artery.

thrombus through the aspiration catheter which is left in place. This technique may, however, prove ineffective or impossible in cases of very firm thrombi, where retraction of the stent retriever and active pinning of the thrombus between the stent retriever and the tip of the IMC provides a strong hold on the thrombus and might be the best method to remove these challenging thrombi. However, even with soft thrombi, the partialcapture technique may be preferable because once the proximal portion of the thrombus enters the aspiration catheter, the maximal aspiration force is exerted. By trying to fully capture a friable thrombus, there is a risk of thrombus shearing and distal embolization due to the loss of aspiration at the catheter tip (Figure 8). A recent single-center, retrospective study of the partial-capture technique in 42 patients reported an $\mathrm{mTICl}$ $2 b-3$ rate of $98 \%$ (mTICl 3 rate of 55\%). ${ }^{41}$ Finally, there are emerging data concerning stent retriever thrombectomy with combined BGC and local aspiration, with promising early results. $^{42}$

Procedural impact on friction-adhesion forces. It should be kept in mind that procedural manipulations can influence the interaction between the thrombus and the vessel wall. Because the coefficient of static friction is greater than that of kinetic 


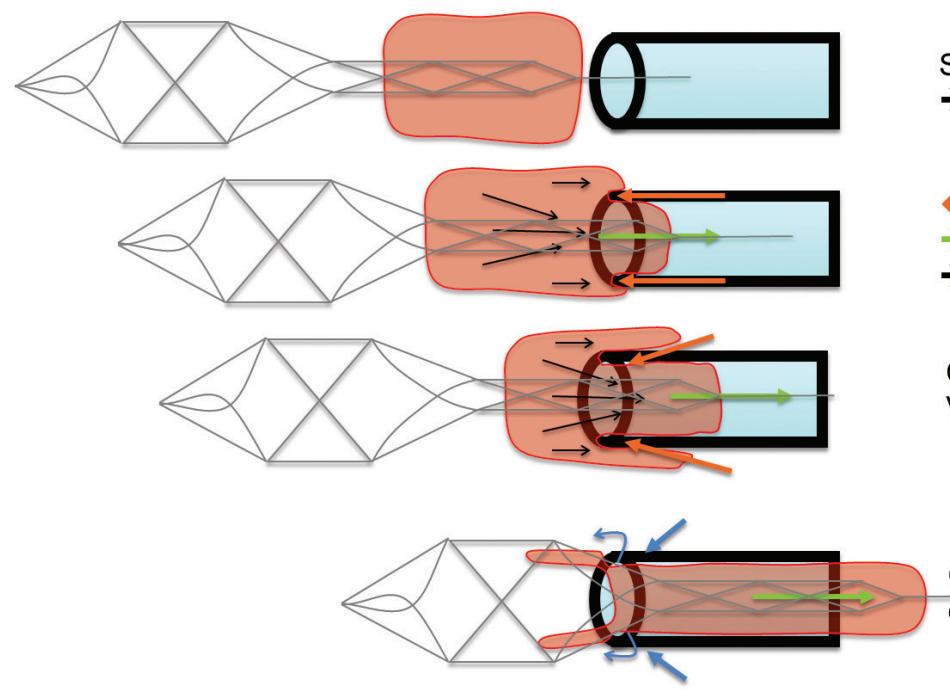

Smaller catheter

$\rightarrow$ clot has to deform more

- Shear resistance

$\rightarrow$ Pull force \& vacuum

$\rightarrow$ Clot pushed outside catheter

Clot is compressed and elongates

Very high shear forces within clot

Risk of clot stripping

(particularly with fresher,

less organized rbc-rich clots)

Clot compressed and elongated

overhang pulled into catheter

Risk of fragmentation, especially if no $B G$

Figure 8. Risk of thrombus shearing when pulling the stent-retriever fully through the aspiration catheter (Courtesy of Neuravi Inc.). BG, balloon guide catheter.

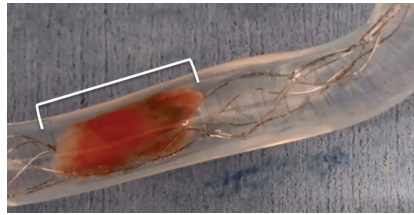

Before stent-retriever pass

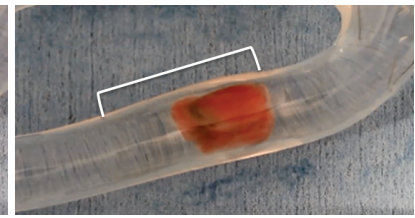

After one pass
Figure 9. Thrombus compression after stent-retriever attempt (Courtesy of Neuravi Inc.).

friction, once the retrieval is begun, the pull should be steady until the thrombus is removed from the body. The retrieval should not be stopped and re-started because greater forces are required to get the thrombus moving again.

Also, with each thrombectomy attempt, there is the potential for compressing the thrombus (Figure 9). With greater compression, the coefficient of friction between the thrombus and vessel wall increases, making subsequent retrieval more difficult (Figure 10). For this reason, identifying techniques that maximize first-pass success are critical. In a related manner, clots that remain in place for a longer time may be increasingly difficult to remove since they are compressed by the waterhammer effect of the systemic blood pressure. This may have implications when embarking on thrombectomy after 6 hours, perhaps even up to 24 hours which was the upper time limit in the recently presented DAWN-trial. ${ }^{43}$

Thromboemboli distal to the M2 segments. Even though none of the randomized controlled trials included clots distal to $M 2$, there are stent retrievers available today with smaller diameter, typically $3 \mathrm{~mm}$, which may be used in smaller arteries. Although distal thrombectomy in the anterior cerebral ar-

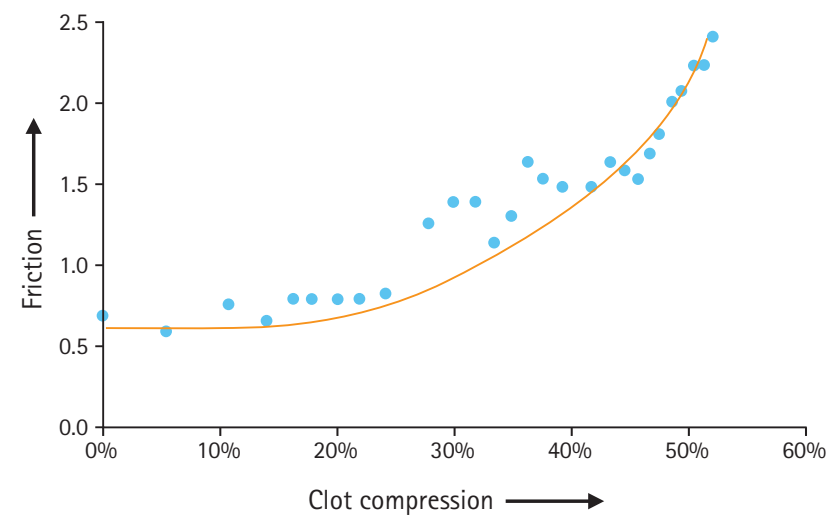

Figure 10. Relationship between thrombus compression and coefficient of friction (Courtesy of Neuravi Inc.).

tery has been reported to have high revascularization rate with low complication profile, ${ }^{44}$ our anecdotal experience suggests that very distal thrombectomy in both the middle and posterior cerebral arteries carries an increased risk for focal subarachnoid hemorrhage and potentially focal ischemia due to perforator injury. Because these distal arteries are less robust and more loosely attached to the parenchyma, a thrombectomy maneuver may displace an entire arterial segment whereby the perforators are at risk for being detached. The risk of injury appears to be greater in the distal superior division MCA branches given their tortuous course along the frontal operculum.

Pharmacological augmentation of mechanical thrombectomy. Intra-arterial thrombolysis, mostly with recombinant tissue plasminogen activator (rt-PA), has been used for quite some time in combination with mechanical thrombectomy in order to initially "soften" the thrombus, or more commonly, to recan- 
alize distal fragments, originally present or dislodged during the procedure. This may imply an increased risk for post-procedure hemorrhage, especially if the patient has been treated with intravenous thrombolysis, but seems in our experience to be safe if the dosage is limited (e.g., $<10 \mathrm{mg}$ rt-PA), particularly after intravenous rt-PA. Another option is to augment the mechanical thrombectomy with intra-arterial administration of GPIIb/IIla inhibitors. Even though this strategy seems safe in small case-series, ${ }_{1}^{45}$ the safety and efficacy need to be proven in larger studies, and many questions remain regarding timing, dosage, routes of administration and the characteristics of specific drugs.

\section{Conclusions and future directions}

Despite the recent success of intra-arterial stroke therapy, there remain numerous challenges for neurointerventionists. Difficult vascular anatomy may preclude access and introduce significant delays to reperfusion. Further work is needed to improve alternative access tools and techniques. Clinical and invitro data suggest that hypodense, fibrin-rich thrombi are more resistant to thrombectomy. However, it is unknown whether a thrombectomy strategy tailored to thrombus imaging characteristics improves angiographic and clinical outcomes. When using a stent-retriever alone, the use of a balloon guide catheter appears beneficial. This is based on nonrandomized clinical data, but is also supported by in-vitro modeling and theoretical considerations. With a closed-cell stent-retriever, deployment using a pushing technique may produce better thrombus integration and yield a greater force of retrieval. Based on recent randomized data from the ASTER trial, the use of aspiration thrombectomy as a first-line approach may be justified even though combined stent-retriever/aspiration approaches, particularly with partial capture of the stent-retriever ("pinning technique"), appear promising for refractory thrombi. Future studies, should examine whether this approach is superior as a first-line approach or if it should be reserved in case of difficulties with straight-forward stent retriever or aspiration techniques. It should be remembered that more complicated techniques may take longer and pose more problems, not least for relatively inexperienced operators; simple and fast is often preferable. With each thrombectomy attempt, there is potential for thrombus compression and increasing difficulty of subsequent retrieval. Therefore, it is essential to identify strategies that enhance first-pass revascularization, as well as rates of complete reperfusion.

Future areas of investigation and innovation: 1) Identify patient subgroups for whom alternative vascular access should be used initially; 2) Improve tools and techniques for direct carotid puncture; 3 ) Investigate reliable imaging predictors of refractory thrombi, and test whether a thrombectomy strategy tailored to thrombus imaging characteristics will improve outcomes; 4) Develop and evaluate thrombectomy approaches that maximize first-pass success and complete reperfusion; and 5) Evaluate the cost effectiveness of using a single- versus multi-device approach as frontline therapy.

\section{Acknowledgments}

The authors gratefully acknowledge David Vale and Michael Gilvarry of Neuravi Inc. for their valuable contributions to this review, including the use of figures and videos from their in vitro modeling.

\section{Supplementary Materials}

Video 1. Friction versus thrombus composition (https://doi. org/10.5853/jos.2017.00752.v001).

Video 2. Stent retriever thrombectomy versus thrombus composition (https://doi.org/10.5853/jos.2017.00752.v002).

\section{References}

1. Berkhemer OA, Fransen PS, Beumer D, van den Berg $L A$, Lingsma $\mathrm{HF}$, Yoo $\mathrm{A}$, et al. $A$ randomized trial of intraarterial treatment for acute ischemic stroke. N Engl J Med 2015; 372:11-20.

2. Goyal $M$, Demchuk AM, Menon BK, Eesa M, Rempel JL, Thornton J, et al. Randomized assessment of rapid endovascular treatment of ischemic stroke. N Engl J Med 2015;372: 1019-1030.

3. Saver JL, Goyal M, Bonafe A, Diener HC, Levy El, Pereira VM, et al. Stent-retriever thrombectomy after intravenous t-PA vs. t-PA alone in stroke. N Engl J Med 2015;372:2285-2295.

4. Jovin TG, Chamorro A, Cobo E, de Miquel MA, Molina CA, Rovira $A$, et al. Thrombectomy within 8 hours after symptom onset in ischemic stroke. N Eng/J Med 2015;372:2296-2306.

5. Campbell BC, Mitchell PJ, Kleinig TJ, Dewey HM, Churilov L, Yassi $N$, et al. Endovascular therapy for ischemic stroke with perfusion-imaging selection. N Engl J Med 2015;372:10091018.

6. Mocco J, Zaidat 00, von Kummer R, Yoo AJ, Gupta R, Lopes $D$, et al. Aspiration thrombectomy after intravenous alteplase versus intravenous alteplase alone. Stroke 2016;47:23312338. 
7. Zaidat 00 , Yoo AJ, Khatri $P$, Tomsick $T A$, von Kummer R, Saver $J \mathrm{~L}$, et al. Recommendations on angiographic revascularization grading standards for acute ischemic stroke: a consensus statement. Stroke 2013;44:2650-2663.

8. Yoo AJ, Simonsen CZ, Prabhakaran S, Chaudhry ZA, Issa MA,

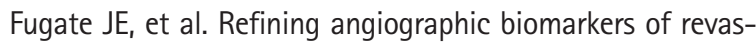
cularization: improving outcome prediction after intra-arterial therapy. Stroke 2013;44:2509-2512.

9. Jansen O, Macho JM, Killer-Oberpfalzer M, Liebeskind D, Wahlgren N, Group TS; TREVO Study Group. Neurothrombectomy for the treatment of acute ischemic stroke: results from the TREVO study. Cerebrovasc Dis 2013;36:218-225.

10. Saver JL, Jahan R, Levy El, Jovin TG, Baxter B, Nogueira RG, et al. Solitaire flow restoration device versus the merci retriever in patients with acute ischaemic stroke (swift): a randomised, parallel-group, non-inferiority trial. Lancet 2012; 380:1241-1249.

11. Nogueira RG, Lutsep $H L$, Gupta R, Jovin TG, Albers GW, Walker $\mathrm{GA}$, et al. Trevo versus merci retrievers for thrombectomy revascularisation of large vessel occlusions in acute ischaemic stroke (trevo 2): a randomised trial. Lancet 2012; 380:1231-1240.

12. Pereira VM, Gralla J, Davalos A, Bonafé A, Castaño C, Chapot $R$, et al. Prospective, multicenter, single-arm study of mechanical thrombectomy using solitaire flow restoration in acute ischemic stroke. Stroke 2013;44:2802-2807.

13. Zaidat 00 , Castonguay AC, Gupta R, Sun $\mathrm{CH}_{1}$ Martin $\mathrm{C}$, Holloway $W E$, et al. North american solitaire stent retriever acute stroke registry: post-marketing revascularization and clinical outcome results. J Neurointerv Surg 2014;6:584-588.

14. Turk AS, Frei $D$, Fiorella $D$, Mocco J, Baxter $B$, Siddiqui $A$, et al. ADAPT FAST study: a direct aspiration first pass technique for acute stroke thrombectomy. J Neurointerv Surg 2014;6: 260-264.

15. Humphries W, Hoit D, Doss VT, Elijovich L, Frei D, Loy D, et al. Distal aspiration with retrievable stent assisted thrombectomy for the treatment of acute ischemic stroke. J Neurointerv Surg 2015;7:90-94.

16. Gratz PP, Schroth G, Gralla J, Mattle HP, Fischer U, Jung S, et al. Whole-brain susceptibility-weighted thrombus imaging in stroke: fragmented thrombi predict worse outcome. AJNR Am J Neuroradiol 2015;36:1277-1282.

17. Madhwal S, Rajagopal V, Bhatt DL, Bajzer CT, Whitlow P, Kapadia SR. Predictors of difficult carotid stenting as determined by aortic arch angiography. J Invasive Cardiol 2008;20: 200-204.

18. Ribo M, Flores A, Rubiera M, Pagola J, Mendonca N, Rodriguez-Luna $D$, et al. Difficult catheter access to the occluded vessel during endovascular treatment of acute ischemic stroke is associated with worse clinical outcome. J Neurointerv Surg 2013;5(Suppl 1):i70-i73.

19. Jadhav $A P$, Ribo M, Grandhi $R$, Linares $G$, Aghaebrahim $A$, Jovin TG, et al. Transcervical access in acute ischemic stroke. $J$ Neurointerv Surg 2014;6:652-657.

20. Mokin M, Snyder KV, Levy El, Hopkins LN, Siddiqui AH. Direct carotid artery puncture access for endovascular treatment of acute ischemic stroke: technical aspects, advantages, and limitations. J Neurointerv Surg 2015;7:108-113.

21. Ruffino MA, Faletti $R$, Bergamasco $L$, Fonio $P$, Righi D. Incidence of new ischaemic brain lesions after carotid artery stenting with the micromesh roadsaver carotid artery stent: a prospective single-centre study. Cardiovasc Intervent Radiol 2016;39:1541-1549.

22. Sivan-Hoffmann R, Gory B, Armoiry X, Goyal M, Riva R, Labeyrie $P E$, et al. Stent-retriever thrombectomy for acute anterior ischemic stroke with tandem occlusion: a systematic review and meta-analysis. Eur Radiol 2017;27:247-254.

23. Goyal M, Menon BK, van Zwam WH, Dippel DW, Mitchell PJ, Demchuk AM, et al. Endovascular thrombectomy after largevessel ischaemic stroke: a meta-analysis of individual patient data from five randomised trials. Lancet 2016;387:17231731.

24. Liebeskind DS, Jahan R, Nogueira RG, Zaidat 00, Saver JL; SWIFT Investigators. Impact of collaterals on successful revascularization in solitaire fr with the intention for thrombectomy. Stroke 2014;45:2036-2040.

25. Gunning GM, McArdle K, Mirza M, Duffy S, Gilvarry M, Brouwer PA. Clot friction variation with fibrin content; implications for resistance to thrombectomy. J Neurointerv Surg 2017. Epub ahead of print.

26. Brinjikji W, Duffy S, Burrows A, Hacke W, Liebeskind D, Majoie $\mathrm{CB}$, et al. Correlation of imaging and histopathology of thrombi in acute ischemic stroke with etiology and outcome: a systematic review. J Neurointerv Surg 2016. Epub ahead of print.

27. Yoo AJ, Mocco J, Zaidat 00, Khatri P, Gupta R, Frei D, et al; THERAPY Trial Investigators. Impact of thrombus length on outcomes after intra-arterial thrombectomy in the therapy trial. European Stroke Organisation Conference; 2016.

28. van der Marel K, Chueh JY, Brooks OW, King RM, Marosfoi $M G$, Langan ET, et al. Quantitative assessment of device-clot interaction for stent retriever thrombectomy. J Neurointerv Surg 2016. Epub ahead of print.

29. Haussen DC, Rebello LC, Nogueira RG. Optimizating clot retrieval in acute stroke: the push and fluff technique for closed-cell stentrievers. Stroke 2015;46:2838-2842. 
30. Mokin M, lonita CN, Nagesh SV, Rudin S, Levy El, Siddiqui $\mathrm{AH}$. Primary stentriever versus combined stentriever plus aspiration thrombectomy approaches: in vitro stroke model comparison. J Neurointerv Surg 2015;7:453-457.

31. Chueh JY, Puri AS, Wakhloo AK, Gounis MJ. Risk of distal embolization with stent retriever thrombectomy and ADAPT. J Neurointerv Surg 2016;8:197-202.

32. Shi $Y$, Cheshire D, Lally F, Roffe $C$. Suction force-suction distance relation during aspiration thrombectomy for ischemic stroke: a computational fluid dynamics study. Physics in Medicine 2017;3:1-8.

33. Lapergue B, Rodesch G, Turjman F, Berge J, Desal H, Mounayer $C_{1}$ et al; ASTER Investigators. Aster trial: primary results, interest of direct aspiration first pass technique for thrombectomy revascularization of large vessel occlusion in acute ischemic stroke. International Stroke Conference; 2017.

34. Chueh JY, Kuhn AL, Puri AS, Wilson SD, Wakhloo AK, Gounis MJ. Reduction in distal emboli with proximal flow control during mechanical thrombectomy: A quantitative in vitro study. Stroke 2013;44:1396-1401.

35. Haussen DC, Bouslama M, Grossberg JA, Nogueira RG. Remote aspiration thrombectomy in large vessel acute ischemic stroke. J Neurointerv Surg 2017;9:250-252.

36. Kim YW, Kang DH, Hwang YH, Park J, Kim YS. Efficacy of proximal aspiration thrombectomy for using balloon-tipped guide catheter in acute intracranial internal carotid artery occlusion. J Korean Neurosurg Soc 2016;59:379-384.

37. Nguyen TN, Malisch $T$, Castonguay AC, Gupta $\mathrm{R}$, Sun $\mathrm{CH}_{\text {, }}$ Martin $\mathrm{CO}$, et al. Balloon guide catheter improves revascularization and clinical outcomes with the solitaire device: Analysis of the north american solitaire acute stroke registry. Stroke 2014;45:141-145.

38. Velasco A, Buerke $B$, Stracke CP, Berkemeyer S, Mosimann PJ, Schwindt $W$, et al. Comparison of a balloon guide catheter and a non-balloon guide catheter for mechanical thrombectomy. Radiology 2016;280:169-176.

39. Lapergue B, Rodesch G, Turjman F, Berge J, Desal H, Mounayer $C_{1}$ et al; ASTER Investigators. Aster trial: Primary results, interest of direct aspiration first pass technique for thrombectomy revascularization of large vessel occlusion in acute ischemic stroke. European Stroke Organisation Conference; 2017.

40. Fargen KM, Arthur AS, Spiotta AM, Lena J, Chaudry I, Turner $R D$, et al. A survey of neurointerventionalists on thrombectomy practices for emergent large vessel occlusions. J Neurointerv Surg 2017:9:142-146.

41. Massari $F$, Henninger $N$, Lozano JD, Patel $A$, Kuhn AL, Howk $M$, et al. Arts (aspiration-retriever technique for stroke): initial clinical experience. Interv Neuroradiol 2016;22:325-332.

42. Stampfl S, Pfaff J, Herweh $C$, Pham M, Schieber S, Ringleb $P A$, et al. Combined proximal balloon occlusion and distal aspiration: a new approach to prevent distal embolization during neurothrombectomy. J Neurointerv Surg 2017;9:346351.

43. Jovin TG, Nogueira RG; DAWN Investigators. Dawn in full daylight (dwi or ctp assessment with clinical mismatch in the triage of wake up and late presenting strokes undergoing neurointervention). European Stroke Organisation Conference; 2017.

44. Pfaff J, Herweh C, Pham M, Schieber S, Ringleb PA, Bendszus $M$, et al. Mechanical thrombectomy of distal occlusions in the anterior cerebral artery: recanalization rates, periprocedural complications, and clinical outcome. AJNR Am J Neuroradio/ 2016;37:673-678.

45. Goh DH, Jin SC, Jeong HW, Ha SY. Mechanical solitaire thrombectomy with low-dose booster tirofiban injection. Neurointervention 2016;11:114-119. 